\title{
Internal Friction Measurements in Nb-0.3 wt. \% Ti Containing Oxygen
}

\author{
C.R. Grandini, L.E.C. Ferreira, H.R.Z. Sandim*, O. Florêncio**, H. Tejima** and J.A.R. Jordão** \\ Departamento de Física, UNESP, 17.033-360, Bauru SP, Brazil \\ * Departamento de Engenharia de Materiais, FAENQUIL, 12.600-000, Lorena SP, Brazil \\ ** Departamento de Fúsica, UFSCar, 13.565-905, São Carlos SP, Brazil
}

\begin{abstract}
Internal friction measurements were made in the $\mathrm{Nb}-\mathrm{Ti}$ alloy containing $0.3 \mathrm{wt} . \%$ of $\mathrm{Ti}$, doped with various quantities of oxygen ( 0.04 to $0.08 \mathrm{wt}$. \%) utilizing a torsion pendulum. These measurements were performed in the temperature range of $300 \mathrm{~K}$ to $700 \mathrm{~K}$ with the oscillation frequency about $1.0 \mathrm{~Hz}$. The experimental results showed relaxation peaks due the stress induced ordering of oxygen atom and pairs of oxygen atom around the niobium atoms (metallic matrix) and around titanium atoms (substitutional solute).
\end{abstract}

\section{INTRODUCTION}

The interest of anelastic relaxation study due to the presence of $\mathrm{O}$ and $\mathrm{N}$ in bcc metals was initiated from work of Snoek [1]. He postulated that the atoms of these gases, dissolved interstitially in octahedral positions of the crystalline lattice, interacted with the metallic matrix by a relaxation process known as stress induced ordering. This reorientation is manifested in the form of peaks in the internal friction spectra, known as Snoek peaks. Hence the Snoek peaks were exhaustively studied, principally the one related to the relaxation processes due stress induced ordering of $\mathrm{O}$ and $\mathrm{N}$ atoms around the niobium atoms of metallic matrix [2-6]. For metallic alloys, for example, $\mathrm{Nb}-\mathrm{Zr}$ [7] and $\mathrm{Nb}-\mathrm{Ti}[8,9]$, such studies are not extensive. In this work we report a internal friction study in the $\mathrm{Nb}-0.3 \mathrm{wt}$. \% Ti alloy, containing different amounts of oxygen in solid solution. The object of this study is to analyse the internal friction spectrum in terms of the constituent peaks owing to the elastic interactions of the interstitials.

\section{EXPERIMENTAL PROCEDURE}

\subsection{Sample Preparation}

$\mathrm{Nb}-\mathrm{Ti}-\mathrm{O}$ alloys were obtained by means of the mechanical mixing of $\mathrm{Nb}$ and $\mathrm{TiO}_{2}$ powders followed by cold isostatic pressing (200 Mpa) and high vacuum sintering. $\mathrm{Nb}$ powder were obtained by the hydridedehydride process $(\mathrm{HDH})$. High-purity $\mathrm{Ti}^{-\mathrm{O}_{2}}$ was supplied by Cerac Inc. Average grain size of $\mathrm{Nb}$ and $\mathrm{TiO}_{2}$ powders were $8 \mu \mathrm{m}$ and $0.3 \mu \mathrm{m}$ respectively. Table 1 shows the typical composition of the materials used in this work. Mixing of powders were carried out in a $\mathrm{Nb}$-lined ball mill containing $\mathrm{Nb}$-ball to avoid contamination. A complete mixing was accomplished after 3 hours. Green compacts showed about $65 \%$ of the theoretical density of pure niobium. Sintering was carried out in resistive furnace at $2100{ }^{\circ} \mathrm{C}$ between 70 and 85 minutes, using a $\mathrm{Nb}$ pipe as heating element. During sintering, oxygen content decrease due to the volitilazation of $\mathrm{NbO}$ and $\mathrm{NbO}_{2}$, depending on the total amount of oxygen $[10,11]$. Dissolution 
of $\mathrm{TiO}_{2}$ particles in $\mathrm{O}$ and $\mathrm{Ti}$ atoms took place during sintering. Titanium content remained practically unchanged after high-vacuum sintering $(0.3 \mathrm{wt}$. \%). After that, sintered bars were cold swaged uo $3.8 \mathrm{~mm}$ of diameter $(\approx 56 \%$ of reduction in area). Oxygen contents of samples A, B and C were respectively $(0.041 \pm 0.006),(0.060 \pm 0.006)$ and $(0.076 \pm 0.007) \mathrm{wt} . \%$ of $\mathrm{O}$. Oxygen and nitrogen were analysed in a TC-136 equipment (Leco Co.) using the technique of sample melting and inert gas carrier. Metallic impurities were determined in a $3410-J C P$ inductively coupled plasma spectrophotometer (ARL).

Table 1. Chemical composition of the powders used in this work.

\begin{tabular}{ccccccc}
\hline \hline Powder & \multicolumn{7}{c}{ Maximum content (wt. \%) } \\
& $\mathrm{O}$ & $\mathrm{N}$ & $\mathrm{Al}$ & $\mathrm{Fe}$ & $\mathrm{Cu}$ & $\mathrm{Si}$ \\
\hline $\mathrm{TiO}_{2}$ & - & - & 0.010 & 0.001 & 0.001 & 0.001 \\
$\mathrm{Nb}$ & 0.620 & 0.038 & 0.003 & 0.004 & 0.001 & 0.003 \\
\hline \hline
\end{tabular}

\subsection{Internal Friction Measurements}

The internal friction spectrum were obtained by an inverted torsion pendulum of Kê type [12] with the sample in the rod form $(0.38 \mathrm{~cm}$. of diameter and $10 \mathrm{~cm}$. long), operating with frequency about $1.3 \mathrm{~Hz}$ in the temperature range of 350 to $550 \mathrm{~K}$. The internal friction measurements were made utilizing the heating rate of $1.0 \mathrm{~K} / \mathrm{min}$. on a vacuum of $10^{-6}$ Torr. The maximum stain amplitude was about $10^{-5}$. The data were acquired by an automatic system which measured the angular velocity of the pendulum about the equilibrium point.

\subsection{Analysis of the Experimental Data}

The internal friction spectrum were resolved into their Snoek peaks (Debye's peaks), analysed by successive subtraction method [13], using the Jandel Peak Fitting software. The analysis was based on the anelastic standard equation for a single relaxation process [14]:

$$
Q^{-1}=Q_{m}^{-1} \operatorname{sech}\left[\frac{E}{k}\left(\frac{1}{T}-\frac{1}{T_{m}}\right)\right]
$$

where: $Q^{-1}$ is the internal friction as a function of $T ; E$ is the activation enthalpy; $Q_{m}^{-1}$ is the intensity of peak occurring at temperature $T_{m}$ and $k$ is the Boltzmann constant.

The analysis of each spectrum was done by its constituent peaks by the iteration of $\mathrm{n}$ processes individually, each one by its three adjustable parameters $\left(Q_{m}^{-1}, E, T_{m}\right)$, until obtaining a better fit.

\section{RESULTS}

Figure 1 shows the internal friction spectrum as a temperature function measured at about $1.3 \mathrm{~Hz}$, for the samples of $\mathrm{Nb}-0.3$ wt. \% $\mathrm{Ti}$, containing about of 0.04 (sample A), 0.06 (sample B) and 0.08 (sample C) wt. \% of oxygen dissolved in solid solution, respectively. We can observe the presence of a relaxation structure consisting of at least two peaks, one bigger and very clear, found at about $430 \mathrm{~K}$ and other smaller, less resolved, at about $476 \mathrm{~K}$. Both peaks increases by increasing the amount of oxygen present in the sample. The figures 2 to 4 represent the internal friction spectrum shown above with the background extracted and plotted as a function of the reciprocal of temperature. The theoretical curves shown there represents the sum of Debye's peaks. In the sample A were observed two peaks. The first one localized at $430 \mathrm{~K}$ was attributed to the relaxation process due the stress induced ordering of an oxygen atom around the $\mathrm{Nb}$ atoms of the metallic matrix. (Nb-O process) and the second peak, with smaller amplitude in comparison with the first one, found at $476 \mathrm{~K}$, was attributed to the relaxation process due 
the stress induced ordering of an oxygen atom around the Ti atoms of the metallic matrix (Ti-O process). The relaxation parameters for these relaxation processes are presented in Table 2 . In the sample B, was identified a third peak, with the amplitude less than the earlier two observed peaks and found at $445 \mathrm{~K}$. The amplitude of the peak attributed to the relaxation process $\mathrm{Nb}-\mathrm{O}$ increased by $70 \%$, while the amplitude of the peak attributed to Ti-O relaxation process increased by $100 \%$. The third peak was attributed to the relaxation process due the stress induced ordering of pairs of oxygen atoms around the niobium atoms of the metallic matrix ( $\mathrm{Nb}-\mathrm{O}-\mathrm{O}$ process). The relaxation parameters for this relaxation process are presented in the Table 2 , too.

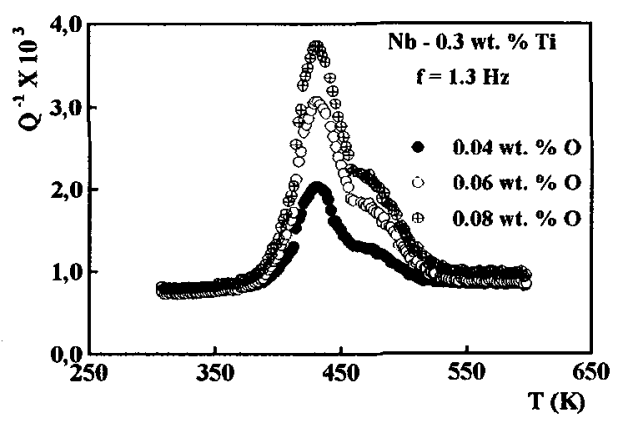

Figure 1. Internal friction vs. temperature for $\mathrm{Nb}-0.3 \mathrm{wt}$. $\% \mathrm{Ti}$, containing three different oxygen quantities in solid solution, measured with frequency around $1.3 \mathrm{~Hz}$.

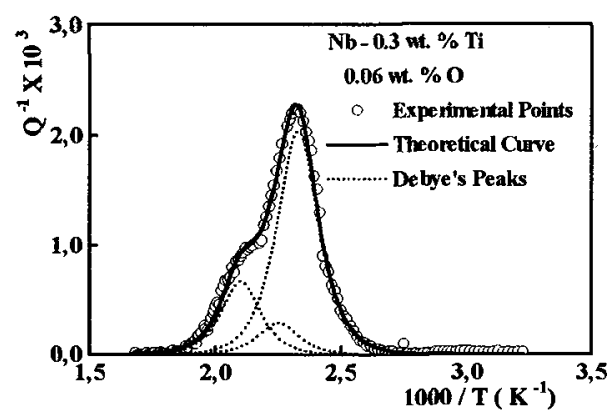

Figure 3. Internal friction vs. inverse of temperature for $\mathrm{Nb}-0.3 \mathrm{wt}$. \% Ti, containing $0.06 \mathrm{wt}$. \% of oxygen in solid solution, measured with frequency around $1.3 \mathrm{~Hz}$, resolved into their constituent Debye's peaks.

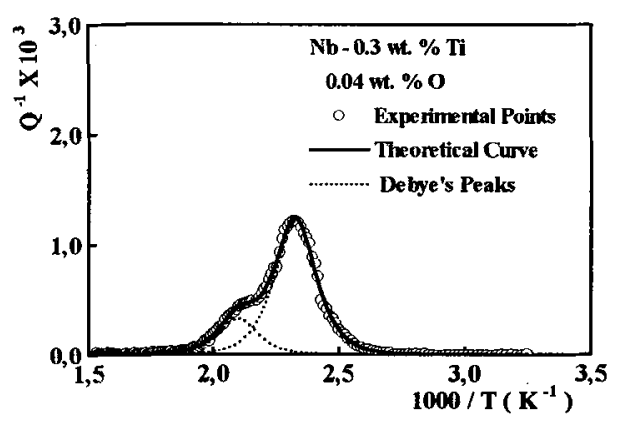

Figure 2. Internal friction vs. inverse of temperature for $\mathrm{Nb}-0.3 \mathrm{wt}$ \% Ti, containing $0.04 \mathrm{wt}$ \% of oxygen in solid solution, measured with frequency around $1.3 \mathrm{~Hz}$, resolved into their constituent Debye's peaks.

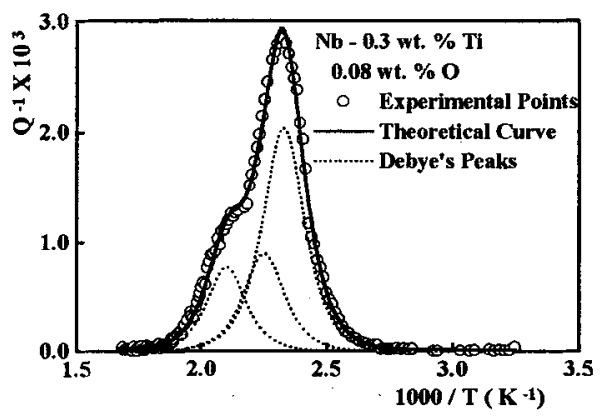

Figure 4. Internal friction vs. inverse of temperature for $\mathrm{Nb}-0.3 \mathrm{wt}$. \% Ti, containing $0.08 \mathrm{wt}$ \% of oxygen in solid solution, measured with frequency around $1.3 \mathrm{~Hz}$, resolved into their constituent Debye's peaks.

In the sample $\mathrm{C}$ also we observed three peaks. The amplitude of the peak attributed to the $\mathrm{Nb}-\mathrm{O}$ relaxation process remained constant, i.e., it saturated. The amplitude of the peak attributed to the Ti-O relaxation process increase $14 \%$ in relation to the earlier sample. The amplitude of the third peak increased $300 \%$ in relation to earlier sample. The relaxation parameters for these relaxation processes are also presented in Table 2.

\section{CONCLUSIONS}

1. Internal friction measurements were made in the $\mathrm{Nb}-0.3 \mathrm{wt} . \% \mathrm{Ti}$ alloys produced by powder metallurgy technique, containing $0.04,0.06$ and $0.08 \mathrm{wt} \%$ of oxygen in solid solution.

2. The obtained relaxation spectrum were analysed in terms of the their constituents Debye's peaks. Were identified peaks attributed to relaxation $\mathrm{Nb}-\mathrm{O}$ (samples $\mathrm{A}, \mathrm{B}$ and $\mathrm{C}$ ); $\mathrm{Nb}-\mathrm{O}-\mathrm{O}$ (samples $\mathrm{B}$ and $\mathrm{C}$ ) and Ti-O (samples A, B and C) 
3. The positions of the peaks were unaltered with respect to the rease of oxygen concentration. The observed values were $430 \mathrm{~K}$ (Nb-O process); 445 ( $\mathrm{Nb}-\mathrm{O}-\mathrm{O}$ process) and $476 \mathrm{~K}$ (Ti-O process).

4. The activation enthalpies of three different process were found to be $1.15 \mathrm{eV}$ (Nb-O process); $1.18 \mathrm{eV}$ (Nb-O-O process) and $1.24 \mathrm{eV}$ ( $\mathrm{Ti}-\mathrm{O}$ process).

Table 2. Relaxation parameters for the relaxation processes found in this work.

\begin{tabular}{|c|c|c|c|c|c|}
\hline System & Frequency $(\mathrm{Hz})$ & Process & $\mathrm{T}(\mathrm{K})$ & $E(e V)$ & Reference \\
\hline \multirow[t]{2}{*}{$\mathrm{Nb}-0.3 \mathrm{Ti}-0.04 \mathrm{O}$} & 1.3 & $\mathrm{Nb}-\mathrm{O}$ & 430 & 1.15 & this work \\
\hline & & $\mathrm{Ti}-\mathrm{O}$ & 476 & 1.24 & this work \\
\hline \multirow[t]{3}{*}{$\mathrm{Nb}-0.3 \mathrm{Ti}-0.06 \mathrm{O}$} & 1.3 & $\mathrm{Nb}-\mathrm{O}$ & 430 & 1.15 & this work \\
\hline & & $\mathrm{Nb}-\mathrm{O}-\mathrm{O}$ & 445 & 1.18 & this work \\
\hline & & Ti-O & 476 & 1.24 & this work \\
\hline \multirow[t]{3}{*}{$\mathrm{Nb}-0.3 \mathrm{Ti}-0.08 \mathrm{O}$} & 1.3 & $\mathrm{Nb}-\mathrm{O}$ & 430 & 1.15 & this work \\
\hline & & $\mathrm{Nb}-\mathrm{O}-\mathrm{O}$ & 445 & 1.18 & this work \\
\hline & & Ti-O & 476 & 1.24 & this work \\
\hline \multirow[t]{4}{*}{$\mathrm{Nb}$} & 1.0 & $\mathrm{Nb}-\mathrm{O}$ & 430 & 1.15 & [2] \\
\hline & & $\mathrm{Nb}-\mathrm{O}-\mathrm{O}$ & 443 & 1.17 & [2] \\
\hline & 1.0 & $\mathrm{Nb}-\mathrm{O}$ & 427 & 1.15 & {$[5]$} \\
\hline & 1.0 & $\mathrm{Nb}-\mathrm{O}$ & 423 & 1.15 & [16] \\
\hline \multirow[t]{2}{*}{$\mathrm{Nb} 2.7 \mathrm{Ti}$} & 1.0 & $\mathrm{Nb}-\mathrm{O}$ & 421 & & {$[8]$} \\
\hline & & Ti-O & 463 & & [8] \\
\hline \multirow[t]{3}{*}{$\mathrm{Nb}-48 \mathrm{Ti}$} & 1.0 & $\mathrm{Nb}-\mathrm{O}$ & 430 & 1.15 & [9] \\
\hline & & $\mathrm{Nb}-\mathrm{O}-\mathrm{O}$ & 443 & 1.21 & [9] \\
\hline & & Ti-O & 467 & 1.23 & [9] \\
\hline
\end{tabular}

\section{Acknowledgements}

The authors thanks FAENQUIL for the samples; CNPq, FAPESP, Capes and PROPP-UNESP for the financial support.

\section{References}

[1] - Snoek J. L., Physica, 8 (1941) 711.

[2] - Ahmad M. S. and Szkopiak Z. C., J. Phys. Chem. Solids, 31 (1970) 1799.

[3] - Weller M., Zhang J. X., Shulze K., Kê T. S. and Diehl J., J. Physique, 42 (1981) C5-817.

[4] - Weller M., Diehl J., Zhang J. X., Hörz G., Mann R. and Shulze K., J. Physique, 46 (1985) C10-47.

[5] - Haneczok G. and Weller M., J. Less-Common Metals, 159 (1990) 269.

[6] - Povolo F. and Lambri O. A., J. Alloys and Comp., 211/212 (1994) 41.

[7] - Botta Fo. W. J., Florêncio O., Grandini C. R., Tejima H. and Jordão J. A. R., Acta Metall. et Mater., 38 (1990) 391.

[8] - Heulin B., Mem. Etudes Sci. Rev. Metall., (1986) 311

[9] - Florêncio O., Botta Fo. W. J., Grandini C. R., Tejima H. and Jordão J. A. R., J. Alloys Comp., 211/212 (1994) 37

[10] - Fromm E. and Hörz G., Intern. Met. Rev., 5/6 (1990) 269.

[11] - Shulze K., Jehn J. A. and Hörz G., J. Metals, 40 (1988) 25.

[12] - Kê T. S., Phys. Review, 71 (1947) 533.

[13] - Grandini C. R., Scalvi R. M. F., Oliveira A. R. G., Florêncio O., Tejima H. and Jordão J. A. R., Revista de Física Aplicada e Instrumentação, 10 (1995) 1.

[14] - Nowick A. S. and Berry B. S., Anelastic Relaxation in Crystalline Solids (Academic Press, New York, 1972).

[15] - Weller M., Zhang J. X., Li G. Y., Kê T. S., Diehl J., Acta Metall, 29 (1981) 1042.

[16] - Weller M., Haneczok G. and Diehl J., Phys. Stat. Solid (b), 172 (1992). 145 